\title{
Solvent Extraction of Vanadium (V) from Phosphate Solutions with Trioctylmethylammonium Chloride (TOMAC)
}

\author{
Onipede, A. E. ${ }^{{ }^{*}}$, Ojo, J. O. ${ }^{2}$ \\ ${ }^{I}$ Department of Science Technology, Federal Polytechnic Ado Ekiti \\ ${ }^{2}$ Department of Industrial Chemistry, Federal University of Technology Akure
}

\begin{abstract}
Different experimental conditions that could affect the extraction of vanadium (V) were investigated. These include acid concentration, metal ion concentration, extractant concentration, temperature, mixing of extractants, extraction stages and addition of foreign ions. TOMAC was found to be more efficient at lower acid concentration (1M). Optimum extraction conditions were reached at $38^{\circ} \mathrm{C}$ and the use of TOMAC proved to be synergistic with the addition $2.5 \%$ TOPO. The infrared and UV-visible spectra data were used to propose $\mathrm{VO}_{2} \mathrm{H}_{2} \mathrm{PO}_{4}$.nTOMAC as the stoichiometry for the organic extract.
\end{abstract}

Keywords: vanadium (V), extractant, phosphoric acid, solvent extraction, TOMAC.

\section{Introduction}

Solvent extraction is a simple technique for separating the components of homogeneous liquid mixture by distribution between the original liquid and a second liquid, which is either immiscible or only partially miscible with the first. Solvent extraction is the separation method of choice where distillation fails. Separation is achieved by adding a solvent to the original liquid carrying the component to be extracted (Sanchez, 1991).

Liquid-liquid extraction also known as solvent extraction partitioning is a method used to separate compounds based on their relative solubility in two different immiscible liquids. It is an extraction of a substance from one liquid phase into another liquid phase. Liquid-liquid extraction is a basic technique in chemical laboratories, where it is performed using a separating funnel (Sanchez, 1991).

Solvent extraction is used in nuclear reprocessing, ore reprocessing (Ritcey and Ashbrook, 2000), the production of fine organic compounds, the processing of perfumes and other industries. This process is continuously by pumping an organic component with the aqueous component and allows ion transfer between them.

The solvent extraction of metals has become increasingly important in connection with hydrometallurgical extraction process. The main areas of application of solvent extraction with reversible chemical reaction are hydrometallurgy and liquid-liquid extraction as applied in metallurgical processing. Apart from separation, solvent extraction can be used for concentration and purification of solute (Scholz, 2000).

The three main separation processes between solid, gas and liquid have long been known, while solvent extraction is a relatively new separation technique. Nevertheless, because all solutes can be made more or less soluble in aqueous and organic phases, the number of applications of solvent extraction is almost limitless (Jan Rydberg et al; 2005).

Since large- scale industrial solvent extraction is a continuous process (in contrast to laboratory batch process) and can be made more selective than the conventional gas-liquid-solid separation technique, it offers numerous industrial possibilities to achieve desired separation efficiently and economically (Jan Rydberg et al; 2005).

\section{Materials used}

Trioctylmethylammonium chloride (TOMAC), phosphoric acid $\left(\mathrm{H}_{3} \mathrm{PO}_{4}\right)$, ammonium metavanadate $\left(\mathrm{NH}_{4} \mathrm{VO}_{3}\right)$, potassium dihydrogen phosphate $\left(\mathrm{KH}_{2} \mathrm{PO}_{4}\right)$, nitric acid $\left(\mathrm{HNO}_{3}\right)$, isodecanol and $\mathrm{n}$-heptane. Reagents were prepared by dissolving a given weight of the sample in aqueous acid in a volumetric flask.

\section{Preparation of stock solutions}

$\mathrm{NH}_{4} \mathrm{VO}_{3}(0.03 \mathrm{M})$ was prepared by dissolving $0.0877 \mathrm{~g}$ of the salt in $\mathrm{H}_{3} \mathrm{PO}_{4}(1-6 \mathrm{M})$ in a $25 \mathrm{~cm}^{3}$ volumetric flask. $0.3402 \mathrm{~g} \mathrm{KH}_{2} \mathrm{PO}_{4}$ was added to the vanadium salt to make $0.1 \mathrm{M}$ solution. A yellow solution was obtained.

A stock solution of $8 \mathrm{M} \mathrm{H}_{3} \mathrm{PO}_{4}$ was prepared by measuring $53 \mathrm{~cm}^{3}$ of conc. $\mathrm{H}_{3} \mathrm{PO}_{4}$ and made up to 100 $\mathrm{cm}^{3}$ with distilled water. Other concentrations $(1 \mathrm{M}, 2 \mathrm{M}, 3 \mathrm{M}, 4 \mathrm{M}, 5 \mathrm{M}$, and $6 \mathrm{M})$ were prepared by appropriate dilutions. $15 \%(\mathrm{v} / \mathrm{v})$ TOMAC was prepared by diluting $15 \mathrm{~cm}^{3}$ pure TOMAC to $100 \mathrm{~cm}^{3}$ with $\mathrm{n}$-heptane. $2.5 \%$, $5 \%$ and $10 \%$ concentrations were prepared by further dilution (Ojo, 2010). 


\section{Experimental procedure for equilibrium studies of vanadium (V) extraction with TOMAC}

Effect of variations in acid concentration, metal ion concentration, extractant concentration, temperature, mixing of extractants, extraction stages and addition of foreign ions on the extraction of $\mathrm{VO}_{2}^{+}$.

Vanadium (V) concentration of $0.03 \mathrm{M}$ was prepared in different $\mathrm{H}_{3} \mathrm{PO}_{4}$ concentrations of $1 \mathrm{M}, 2 \mathrm{M}, 3 \mathrm{M}$, $4 \mathrm{M}, 5 \mathrm{M}$ and $6 \mathrm{M}$. A volume of $10 \mathrm{~cm}^{3}$ of each of the solutions was measured into a $100 \mathrm{~cm}^{3}$ separating funnel and $10 \mathrm{~cm}^{3} 10 \%(\mathrm{v} / \mathrm{v})$ extractant (TOMAC in $\mathrm{n}$-heptane) was added to it. The mixture was manually shaken after the cork has been put in place for 5 minutes. The solution was allowed to stand for about a minute with the cork removed to release the pressure in the funnel and also for proper separation of the phases.

The bottom aqueous layer was drawn off into a clean $25 \mathrm{~cm}^{3}$ measuring cylinder. The volume was recorded and stored in a clean reagent bottle labelled as sample ' $\mathrm{A}$ '. The small amount of liquid at the interphase was released from the tap and discarded. The upper organic layer was poured from the top of the funnel into a clean $25 \mathrm{~cm}^{3}$ measuring cylinder and the volume recorded.

The organic layer was transferred to another separating funnel and equal amount of $2 \mathrm{M} \mathrm{HNO}_{3}$ was added as strippant to back extract the organic phase. The mixture was again shaken for another 5 minutes. After standing for about a minute for proper separation, the bottom aqueous layer was released into a measuring cylinder and the volume recorded. It was then transferred into a reagent bottle labelled as sample ' $\mathrm{B}$ '. The stored samples were kept for further analysis. The upper organic layer of extractant was collected in a bottle for possible reuse. Formation of three layers encountered was dispersed with addition of 3-5 drops of isodecanol (a modifier). Vanadium was determined by the phosphotungstate spectrophotometric method (Sanchez-Vinas et al, 1999) which was carried out as follows: $0.1 \mathrm{~cm}^{3}$ of sample was pipetted into $10 \mathrm{~cm}^{3} 0.2 \mathrm{M} \mathrm{H}_{2} \mathrm{SO}_{4}$ in a clean beaker. $2.5 \mathrm{~cm}^{3}$ of $1: 2$ phosphoric acid and $2.5 \mathrm{~cm}^{3}$ of $10 \%$ sodium tungstate were added to it. The solution was made up to $20 \mathrm{~cm}^{3}$ with distilled water. It was heated to boiling, cooled and made up with distilled water in a 25 $\mathrm{cm}^{3}$ standard flask. The absorbance was read at $400 \mathrm{~nm}$ against a blank. The absorbance of standard vanadium solution was also read at the same wavelength (Thorton, 1992; Zygmunt, 1986). The amount of vanadium in sample was calculated from Beer-Lambert equation.

$\mathrm{A} \infty \mathrm{CL}$ Where, $\mathrm{A}$ is the absorbance, $\mathrm{C}$ is the concentration and $\mathrm{L}$ is the path length which is equal to $1 \mathrm{~cm}$ (Vogel, 1989).

\section{Results and discussion}

Table 1 Effect of Acid Concentration on V(V) Extraction from Phosphoric Acid Slutions with TOMAC $[\mathrm{V}(\mathrm{V})]=0.03 \mathrm{M},\left[\mathrm{KH}_{2} \mathrm{PO}_{4}\right]=0.1 \mathrm{M}, \mathrm{TOMAC}=10 \%(\mathrm{v} / \mathrm{v})$

\begin{tabular}{ccccc}
\hline$\left[\mathrm{H}_{3} \mathrm{PO}_{4}\right]$ & {$[\mathrm{V}(\mathrm{V})]_{\mathrm{a}} \mathrm{mol} \mathrm{dm}^{-3}$} & {$[\mathrm{~V}(\mathrm{~V})]_{\text {org }} \mathrm{mol} \mathrm{dm}^{-3}$} & $\mathrm{D}$ & $\mathrm{E}(\%)$ \\
$1 \mathrm{M}$ & 0.012 & 0.018 & 1.500 & 60.0 \\
$2 \mathrm{M}$ & 0.018 & 0.012 & 0.667 & 40.0 \\
$3 \mathrm{M}$ & 0.020 & 0.010 & 0.500 & 33.3 \\
$4 \mathrm{M}$ & 0.022 & 0.008 & 0.364 & 26.7 \\
$5 \mathrm{M}$ & 0.019 & 0.011 & 0.579 & 36.7 \\
$6 \mathrm{M}$ & 0.019 & 0.011 & 0.579 & 36.7 \\
\hline
\end{tabular}

Table 2 Effect of Metal Ion Concentration on V(V) Extraction from Phosphoric Acid Solutions with TOMAC

\begin{tabular}{ccccc}
\hline$[\mathrm{V}(\mathrm{V})]$ & {$[\mathrm{V}(\mathrm{V})]_{\mathrm{a}} \mathrm{mol} \mathrm{dm}^{-3}$} & {$[\mathrm{~V}(\mathrm{~V})]_{\text {org }} \mathrm{mol} \mathrm{dm}^{-3}$} & $\mathrm{D}$ & $\mathrm{E}(\%)$ \\
\hline $0.01 \mathrm{M}$ & 0.006 & 0.004 & 0.667 & 40.0 \\
$0.02 \mathrm{M}$ & 0.012 & 0.008 & 0.667 & 40.0 \\
$0.03 \mathrm{M}$ & 0.012 & 0.018 & 1.500 & 60.0 \\
$0.04 \mathrm{M}$ & 0.016 & 0.024 & 1.500 & 60.0 \\
$0.05 \mathrm{M}$ & 0.016 & 0.034 & 2.125 & 68.0 \\
\hline
\end{tabular}

$\left[\mathrm{H}_{3} \mathrm{PO}_{4}\right]=1 \mathrm{M},\left[\mathrm{KH}_{2} \mathrm{PO}_{4}\right]=0.1 \mathrm{M}$, TOMAC $=10 \%(\mathrm{v} / \mathrm{v})$

Table 3 Effect of Extractant Concentration on V(V) Extraction from Phosphoric Acid Solutions with

\begin{tabular}{lcccc}
\multicolumn{5}{c}{ TOMAC } \\
\hline$[$ TOMAC $]$ & {$[\mathrm{V}(\mathrm{V})]_{\mathrm{a}} \mathrm{mol} \mathrm{dm}^{-3}$} & {$[\mathrm{~V}(\mathrm{~V})]_{\mathrm{org}} \mathrm{mol} \mathrm{dm}^{-3}$} & $\mathrm{D}$ & $\mathrm{E}(\%)$ \\
\hline $2.5 \%$ & 0.014 & 0.016 & 1.143 & \\
$5 \%$ & 0.013 & 0.017 & 1.308 & 53.3 \\
$10 \%$ & 0.012 & 0.018 & 1.500 & 6.7 \\
$15 \%$ & 0.011 & 0.019 & 1.727 & 60.0 \\
\hline
\end{tabular}


Solvent Extraction of Vanadium (V) from Phosphate Solutions with rioctylmethylammonium ....

\begin{tabular}{ccccc} 
Table 4 & Effect of Temperature on V(V) Extraction from Phosphoric Acid Solutions with TOMAC \\
\hline Temp $\left({ }^{0} \mathrm{C}\right)$ & {$[\mathrm{V}(\mathrm{V})]_{\mathrm{a}} \mathrm{mol} \mathrm{dm}^{-3}$} & {$[\mathrm{~V}(\mathrm{~V})]_{\text {org }} \mathrm{mol} \mathrm{dm}^{-3}$} & $\mathrm{D}$ & $\mathrm{E}(\%)$ \\
\hline 28.0 & 0.011 & 0.019 & 1.727 & 63.3 \\
33.0 & 0.010 & 0.020 & 2.000 & 66.7 \\
38.0 & 0.010 & 0.020 & 2.000 & 66.7 \\
43.0 & 0.012 & 0.018 & 1.500 & 60.0 \\
48.0 & 0.011 & 0.019 & 1.727 & 63.3 \\
\hline
\end{tabular}

$[\mathrm{V}(\mathrm{V})]=0.03 \mathrm{M},\left[\mathrm{H}_{3} \mathrm{PO}_{4}\right]=1 \mathrm{M},\left[\mathrm{KH}_{2} \mathrm{PO} 4\right]=0.1 \mathrm{M}, \mathrm{TOMAC}=15 \%(\mathrm{v} / \mathrm{v})$

Table 5 Effect of Mixing of Extractants on V(V) Extraction from Phosphoric acid Solutions

\begin{tabular}{lcccc}
\hline \multicolumn{1}{c}{ Extractant Mixture } & {$[\mathrm{V}(\mathrm{V})]_{\mathrm{a}} \mathrm{mol} \mathrm{dm}^{-3}$} & {$[\mathrm{~V}(\mathrm{~V})]_{\mathrm{org}} \mathrm{mol} \mathrm{dm}^{-3}$} & $\mathrm{D}$ & $\mathrm{E}(\%)$ \\
\hline 15\%TOMAC+ & 0.018 TRPO & 0.012 & 0.667 & 40.0 \\
15\%TOMAC+ $2.5 \%$ TOPO & 0.010 & 0.020 & 2.000 & 66.7 \\
15\%TOMAC+ $10 \%$ D2EHPA & 0.011 & 0.019 & 1.727 & 63.3 \\
\hline
\end{tabular}

$[\mathrm{V}(\mathrm{V})]=0.03 \mathrm{M},\left[\mathrm{KH}_{2} \mathrm{PO}_{4}\right]=0.1 \mathrm{M}, \mathrm{Temp}=48^{0} \mathrm{C}$

Table 6 Effect of Extraction Stages on V(V) Recovery from Phosphoric Acid Solutions with TOMAC

\begin{tabular}{|c|c|c|c|c|}
\hline Stages & {$[\mathrm{V}(\mathrm{V})]_{\mathrm{a}} \mathrm{mol} \mathrm{dm}^{-3}$} & {$[\mathrm{~V}(\mathrm{~V})]_{\text {org }} \mathrm{mol} \mathrm{dm}^{-3}$} & $\mathrm{D}$ & $\mathrm{E}(\%)$ \\
\hline $1^{\text {st }}$ & 0.0082 & 0.0218 & 2.659 & 72.7 \\
\hline $2^{\text {nd }}$ & 0.0042 & 0.0040 & 0.952 & 48.8 \\
\hline $3^{\text {rd }}$ & 0.0040 & 0.0002 & 0.050 & 4.8 \\
\hline
\end{tabular}

$[\mathrm{V}(\mathrm{V})]=0.03 \mathrm{M},\left[\mathrm{H}_{3} \mathrm{PO}_{4}\right]=1 \mathrm{M},\left[\mathrm{KH}_{2} \mathrm{PO}_{4}\right]=0.1 \mathrm{M}, \mathrm{TOMAC}=15 \%(\mathrm{v} / \mathrm{v}), \mathrm{Temp}=48^{0} \mathrm{C}$

Table 7 Effect of Foreign Ions on V(V) Extraction from Phosphoric Acid Solutions with TOMAC

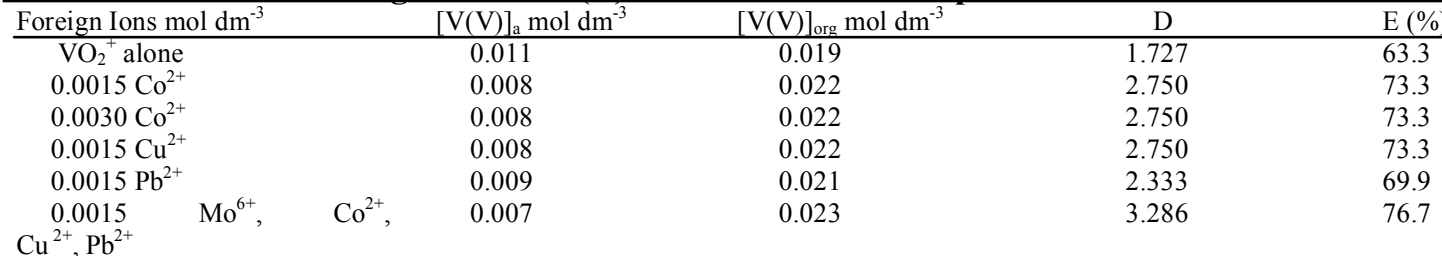

$[\mathrm{V}(\mathrm{V})]=0.03 \mathrm{M},\left[\mathrm{H}_{3} \mathrm{PO}_{4}\right]=1 \mathrm{M},\left[\mathrm{KH}_{2} \mathrm{PO}_{4}\right]=0.1 \mathrm{M}, \mathrm{TOMAC}=15 \%(\mathrm{v} / \mathrm{v}), \mathrm{Temp}=48^{0} \mathrm{C}$

Table 8 Electronic Absorption Spectra for Extracted V(V) from $\mathrm{H}_{3} \mathrm{PO}_{4}$ Solutions with TOMAC

\begin{tabular}{lll}
\hline Compound & Wave number $\left(\mathrm{cm}^{-1}\right)$ & Assignment
\end{tabular}

\begin{tabular}{lll}
\hline $\mathrm{V}(\mathrm{V}) / \mathrm{H}_{3} \mathrm{PO}_{4}(\mathrm{aq})$ & $34014(\mathrm{~s})$ & charge transfer \\
$\mathrm{V}(\mathrm{V})$. TOMAC Complex & $35211(\mathrm{~s})$ & charge transfer
\end{tabular}

Table 9 Infrared Spectra Data for TOMAC and TOMAC Complex

\begin{tabular}{lcc}
\hline Compound & Wave number $\left(\mathrm{cm}^{-1}\right)$ & Assignment \\
\hline TOMAC & $2930(\mathrm{w})$ & $v(\mathrm{C}-\mathrm{H})$ \\
& $1301(\mathrm{w})$ & $\mathrm{v}(\mathrm{C}-\mathrm{N})$ \\
& $723(\mathrm{~s})$ & $\mathrm{v}(\mathrm{V}=\mathrm{O})$ \\
TOMAC Complex & $3404(\mathrm{br})$ & $\mathrm{v}(\mathrm{C}-\mathrm{OH})$ \\
& $2371(\mathrm{w})$ & $v(\mathrm{C}-\mathrm{H})$ \\
& $1320(\mathrm{~s})$ & $\mathrm{v}(\mathrm{C}-\mathrm{N})$ \\
& $717(\mathrm{~s})$ & $\mathrm{v}(\mathrm{V}=\mathrm{O})$ \\
& $3327(\mathrm{br})$ & $\mathrm{v}(\mathrm{C}-\mathrm{OH})$ \\
\hline
\end{tabular}

$\overline{b r}=$ broad

\section{Discussion}

The percentage $\mathrm{VO}_{2}{ }^{+}$extracted showed a gradual decrease with increase in acid concentration. The highest percentage extraction was recorded at $1 \mathrm{M}$ acid concentration $(\mathrm{E} \%=60.0) .1 \mathrm{M} \mathrm{H}_{3} \mathrm{PO}_{4}$ concentration was subsequently used for the extraction of $\mathrm{VO}_{2}^{+}$with TOMAC.

A step-like increase in the percentage extraction of $\mathrm{VO}_{2}^{+}$was recorded. Higher concentrations of the metal ion favours a high extraction of $\mathrm{VO}_{2}{ }^{+} .0 .05 \mathrm{M} \mathrm{V}(\mathrm{V})$ recorded the highest $\mathrm{E} \%$ of 68.0 . This contrasts with Khan et al., 2010 using cloud point extraction (CPE) method to determine trace quantity of vanadium in various pharmaceutical preparations. 
There was a gradual increase in percentage extraction of $\mathrm{V}(\mathrm{V})$ as TOMAC concentration increases from $2.5 \%$ to $15 \%$. The highest $\mathrm{E} \%$ of 63.3 was recorded at $15 \%(\mathrm{v} / \mathrm{v})$ TOMAC. $10 \%(\mathrm{v} / \mathrm{v})$ TOMAC was favoured for further use due to the high viscosity of $15 \%$ concentration.

There was an initial increase in percentage extraction of $\mathrm{V}(\mathrm{V})$ up to $38^{\circ} \mathrm{C}$ after which a drop was recorded and later increase at $48^{\circ} \mathrm{C}$. The increased efficiency of TOMAC at elevated temperatures indicates an endothermic process $(\mathrm{Ojo}, 2009)$.

The percentage extraction of $\mathrm{V}(\mathrm{V})$ with TOMAC was increased by the addition of $2.5 \%(\mathrm{w} / \mathrm{v})$ TOPO from 63.3 (when TOMAC alone was used) to 66.7. This is reasonable as TOPO is a solvating extractant which increases the solubility of the metal in the organic phase. However, TBP has been shown to be antagonistic with D2EHPA in the extraction of $\mathrm{VO}_{2}{ }^{+}$from $\mathrm{HNO} 3$ solutions (Ojo, 2010).

The $\mathrm{V}(\mathrm{V})$ was well extracted from $\mathrm{H}_{3} \mathrm{PO}_{4}$ solution by TOMAC at $48^{\circ} \mathrm{C}$. First stage recorded the highest $\mathrm{E} \%$ of 72.7 which showed drastic reduction in the second and third stages of extraction.

All the foreign ions added to $\mathrm{V}(\mathrm{V})$ in extraction with TOMAC enhanced the extraction of $\mathrm{V}(\mathrm{V})$. The inclusion of $0.0015 \mathrm{M}$ each of all four ions $\left(\mathrm{Mo}^{6+}, \mathrm{Co}^{2+}, \mathrm{Cu}^{2+}\right.$ and $\left.\mathrm{Pb}^{2+}\right)$ recorded the highest $\mathrm{E} \%$ for $\mathrm{V}(\mathrm{V})(\mathrm{E} \%=$ 76.7). TOMAC can therefore find application in the industrial recovery of vanadium from metal scraps in the presence of other metal ions.

The electronic absorption spectra of the aqueous phase and organic extract from $\mathrm{H}_{3} \mathrm{PO}_{4}$ solution by TOMAC recorded two important bands at $34014 \mathrm{~cm}^{-1}$ and $35211 \mathrm{~cm}^{-1}$. The bands have been assigned to charge transfer and they are also of strong absorption. This relates well with the extraction of vanadium (V) from 12M sulphuric acid by Kurbatova and Kurbatov, 2006.

The IR spectra absorption bands for TOMAC and TOMAC complex obtained from the organic extract shows IR absorptions at $2371 \mathrm{~cm}^{-1}, 1320 \mathrm{~cm}^{-1}, 717 \mathrm{~cm}^{-1}$ and $3327 \mathrm{~cm}^{-1}$ which have been assigned to $\mathrm{v}(\mathrm{C}-\mathrm{H})$, $v(\mathrm{C}-\mathrm{N}), \mathrm{v}(\mathrm{V}=\mathrm{O})$ and $\mathrm{v}(\mathrm{C}-\mathrm{OH})$ stretch respectively. The $\mathrm{v}(\mathrm{V}=\mathrm{O})$ band is an evidence for vanadium extraction.

\section{Conclusion}

The following conclusions are drawn from investigating the percentage extraction capabilities of trioctylmethylammonium chloride (TOMAC) as extractant for the extraction of $\mathrm{V}(\mathrm{V})$ from $\mathrm{H}_{3} \mathrm{PO}_{4}$ solutions.

1. TOMAC proved to be very efficient in the extraction of $\mathrm{V}(\mathrm{V})$ from phosphoric acid solutions.

2. TOMAC produced the highest percentage $\mathrm{V}(\mathrm{V})$ extraction when other metal ions were introduced into the solution.

3. The high viscosity of TOMAC limits its usage at higher concentrations.

4. The following is proposed for the stoichiometry of the organic extract of TOMAC $\mathrm{VO}_{2} \mathrm{H}_{2} \mathrm{PO}_{4} \cdot \mathrm{nTOMAC}$.

\section{References}

[1]. Jan Rydberg, Michael Cox, Claude Musikas and Gregory R. Choppin: "Solvent Extraction Principles and Practice" Marcel Dekker Inc. New York, 2nd edition, pp 4-6, 2005.

[2]. Khan, S; Kazi, T.G; Baig, J.A; Kolachi, N.F; Afridi, H.I; Wadhwa, S.K; Shah, A.Q; Kandhro, G.A. and Shah, F: "Cloud Point Extraction of Vanadium in Pharmaceutical Formulations, Dialysate and Parenteral Solutions Using 8-hydroxyquinoline and nonionic Surfactant”. Journal of Hazardous Materials in Analytical Chemistry, Pakistan, vol 182 (1-3) pp 371-376, 2010.

[3]. Kurbatova, L.D. and Kurbatov, D.I: "Extraction Recovery of Vanadium (V) from Sulphuric Acid Solution". Russian Journal of Applied Chemistry vol 79 (5) pp 862-864, 2006.

[4]. Ojo, J.O: "Solvent Extraction of Vanadium (V) from Nitric Acid Solutions with di (2-ethylhexyl) phosphoric acid and tri-n-butyl phosphate". Malaysian Journal of Chemistry, 12 (1) pp 40-48, 2010.

[5]. Ojo, J.O: Solvent Extraction of Vanadium (V) from Nitric Acid Solutions with di (2-ethylhexyl) phosphoric acid and tri-n-butyl phosphate. Malaysian Journal of Chemistry, 12 (1) pp 40-48, 2010.

[6]. Ritcey, G.M. and Ashbrook, A.W: "Solvent Extraction Principles and Application to Process Metallurgy Part I"I. Elsevier Scientific Publishing Company, New York, USA, pp 1-65, 1984.

[7]. Sanchez, A; Caro, C.G. and Jimceaz, N.A: "Extract-photometric Determination of Vanadium (V) with 3 -indoleacetohydroxamic acids". Fresenius Journal of Analytical Chemistry, pp 167-172, 1991.

[8]. Sanchez-Vinas, M; Bagur, G. M; Gazquez, D; Camino, M and Romero R.: "Determination of Tin, Vanadium, Iron and Molybdenum in various Matrices by Atomic Absorption Spectrometry Using a Simultaneous Liquid-liquid Extraction Procedure". Journal of Analytical Toxicology, vol 23 pp 108- 112, 1999.

[9]. Scholz, F.S; Konorsky, L. and Lovric, M.: "A New Access to Gibb"es Energies of Transfer of Ions across Liquid". Electrochemical Communication pp 112-118. Ancient Damascus steel blades. Journal of The Minerals, Metals and Materials Society vol 50 (9) pp 58-64, 2000.

[10]. Thorton, J.D.: "Science and Practice of the Liquid-Liquid Extraction" vol 2. Clarendom Press, Oxford, pp 36-39, 1992.

[11]. Vogel, A.I.: "Vogele"s Textbook of Quantitative Inorganic Analysis". 5th Edition Longman Group Limited, London. Pp 752, 1989.

[12]. Zygmunt Marczenko: "Separation and Spectrophotometric Determination of Elements". Ellis Horwood, Series in Analytical Chemistry, 2nd edition, pp 26, 1986. 